\title{
OBITUARY
}

\section{S. Harvey Mudd}

Published online: 28 February 2014

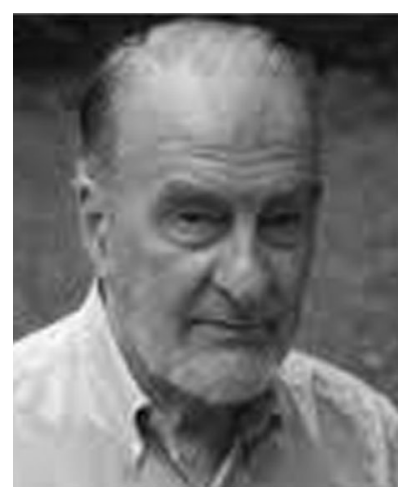

Scientist emeritus in the Laboratory of Molecular Biology, National Institute of Mental Health, NIH, Bethesda MD, USA (b 29/04/1927 Bryn Mawr PA; q. MD Harvard University 1953) died from pneumonia following heart surgery on 21/01/2014.

The death of Harvey Mudd at the age of 86 has immensely saddened our metabolic community. He was the doyen of methionine metabolism and the most generous and humble colleague. An email this week from William Gahl says that, "We have lost a generation of biochemistry in a single man".

Harvey graduated from Harvard in 1949, completing his MD in 1953. After internship and a research fellowship he joined NIH in 1956, working on aspects of methionine synthesis. His third paper was a 1957 letter to Nature, something few ever achieve, and altogether he has published widely, largely on aspects related to the transsulphuration pathway. His publications, almost all in top journals, illustrate his careful pursuit of new aspects of biochemistry. In 1964 he published in Science proof of the enzymatic defect in homocystinuria (cystathionine $\beta$-synthase deficiency). He made many more significant contributions in the homocysteine field, including the first description of homocystinuria and methylmalonic aciduria $(\mathrm{CblC})$ due to a remethylating defect. A seminal study resulted in the 1985 paper in the American Journal of Human Genetics (cited over 800 times) describing the natural history of homocystinuria and proving the beneficial clinical response to pyridoxine for biochemical responders. Later work was on glycine N-methyl transferase and methionine adenosyl transferase deficiencies.

Harvey "retired" in 1988, moving to emeritus status, and publishing over 50 papers post-retirement. He was working on several projects at the time of his death, and was always a thoughtful and generous collaborator. He had many more strings to his bow than biochemistry, one being serious birdwatching, with his wife Marion and friends the world over. He is survived by Marion, their children Susan, Lincoln and Dan, his brother and sister and other close family members.

Bridget Wilcken 